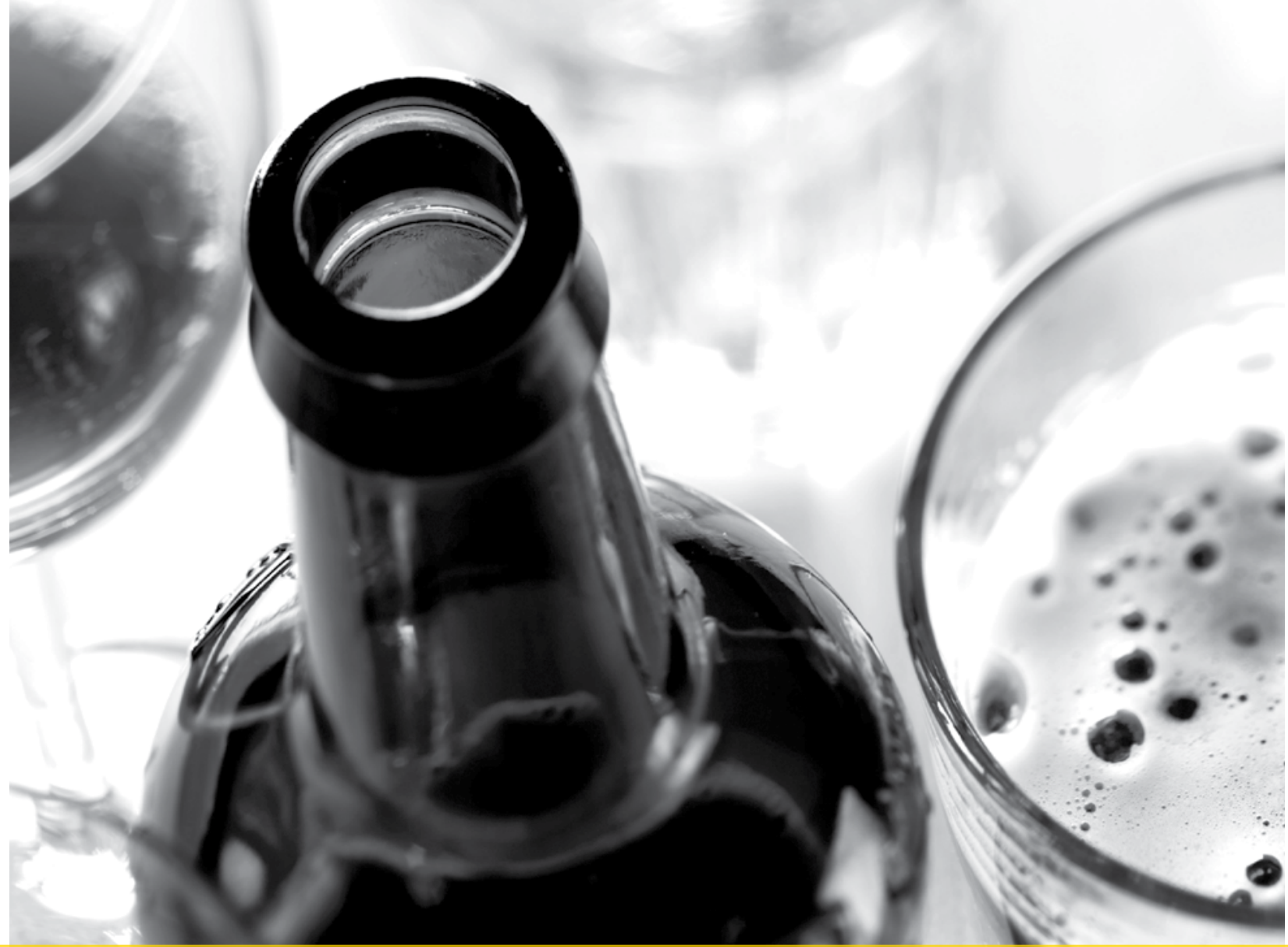

\title{
AS CONSTRUÇÕES \\ MITOLÓGICAS E ARQUETÍPICAS EM PUBLICIDADES DE BEBIDAS ALCOÓLICAS
}

RICARDO ALEXINO FERREIRA 


\section{RESUMO}

Este artigo pretende analisar a apropriação que a publicidade faz na contemporaneidade das narrativas mitológicas através de estudo de caso das campanhas Johnnie Walker, em que é possível perceber o quanto elas trabalham os elementos arquetípicos e antropomórficos. A publicidade atual tem usado bastante esse recurso, tornando-se muito mais conceitual e impactante.

Palavras-chave: mitologia, arquétipos, mídia, publicidade, campanhas de prevenção.

\section{ABSTRACT}

This article aims at analyzing the way contemporary advertising and marketing practices make use of mythological narratives. It does that by presenting the case study of Johnnie Walker campaigns, in which one can notice how much they employ archetypal and anthropomorphic elements. Current advertising has widely used this resource; and has made it much more conceptual and stirring.

Keywords: mythology, archetypes, media, advertising and marketing, prevention campaigns. 


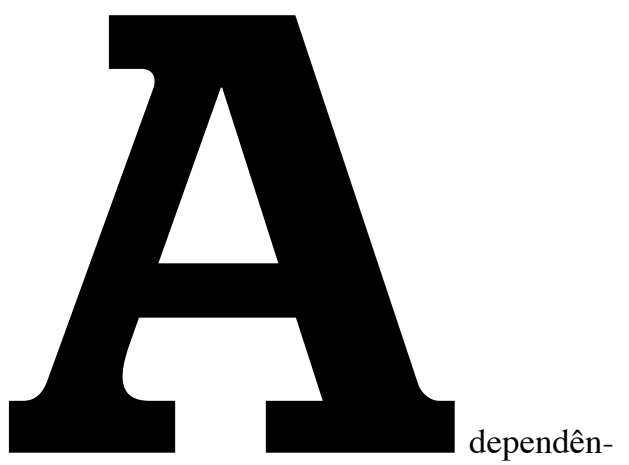

cia química e o uso de drogas (lícitas e ilícitas) na contemporaneidade estão presentes nas pautas das políticas públicas de diferentes governos, entidades civis e também da imprensa (agenda-setting). Nesse sentido, o enfoque dado ao assunto é sempre sobre a dependência, o tratamento e na droga em si.

Porém, ao fazer a interseção entre mitologia e publicidade, é possível perceber que historicamente as narrativas mitológicas têm como tema recorrente o uso de diferentes substâncias que são utilizadas para alterar o estado de consciência do indivíduo. Esses relatos são frequentemente apontados não apenas nas tramas do mito mas também em seus derivados, como contos e lendas, e no campo midiático.

Para citar alguns exemplos do uso de diferentes substâncias para alteração do estado de consciência nas construções mitológicas, há o mito de Eros e Psiquê, resgatado por Lucius Apuleio (125 a 180 a.C.) da tradição oral, em que a personagem central abre a caixa do sono oferecida por Perséfone, que a faz adormecer profundamente. Ao acordar desse sono, resgatada por Eros, Psiquê se transforma existencialmente.

No conto "A Bela Adormecida", de Giambattista Basile (1634), depois recontado nas versões de Charles Perrault (1697) e dos Irmãos Grimm (1812), a personagem central é picada pela agulha envenenada do tear e adormece. Assim como no mito de Psiquê, ela se transforma existencialmente ao acordar cem anos depois.

Em relação às bebidas à base de álcool, elas também estão presentes em muitas narrativas mitológicas e nos contos e lendas. Os mais conhecidos personagens mitológicos das bebidas fermentadas são o deus do vinho e das festas conhecido como Dioniso (na mitologia grega) e Baco (na mitologia romana).

Em mitologias de outros povos, personagens associados às bebidas que alteram o estado de consciência são mencionados fartamente. Na mitologia africana, por exemplo, o ritual de bebidas alcoólicas também é frequente, como no ato da libação (ato de aspergir um líquido em intenção ou em honra de um antepassado ou divindade, conhecido também como "dar pro santo") e o uso do maluvo (vinho-de-palmeira), dentre outros.

Os diferentes usos de substâncias que alteram o estado de consciência, incluindo o álcool, estão presentes nas narrativas mitológicas como agentes imprescindíveis na transformação do indivíduo e nos seus rituais de passagem. Daí a ênfase no ato de usar substâncias que deflagrariam esse processo transformador. A perspectiva é a busca da subjetividade.

A comunicação midiática, especialmente a publicidade, capta com muita eficiência as construções mitológicas e as suas subjetividades e as transforma em peças publicitárias que impactam o público e reforçam o inconsciente coletivo. Algumas peças publicitárias de produtos alcoólicos utilizam essa carga simbólica. Porém, enquanto a alteração do estado de consciência nas narrativas mitológicas se associa aos ritos de passagem, na publicidade essa apropriação está na maior parte das vezes atrelada à reificação.

O principal ponto em comum entre narrativas mitológicas e algumas peças publicitárias é a percepção de que o uso de substâncias para alterar o estado de consciência e proporcionar a sua transcendência é inerente ao ser humano. A compreensão desse fenô-
RICARDO ALEXINO FERREIRA é professor livre-docente da Escola de Comunicações e Artes (ECA) da USP. 
meno passa ao largo de muitas campanhas das políticas públicas de prevenção ao uso de drogas, principalmente o álcool, considerado lícito, pois não levam em consideração tais elementos metafóricos e simbólicos, e acabam por dar ênfase à negação e, consequentemente, à voz imperativa do "faça isso" ou "não faça aquilo".

É interessante perceber que em todas as narrativas mitológicas o proibido sempre incita o personagem a fazê-lo. A negação, na mitologia, implica afirmação. Daí a publicidade, que trabalha no nível do imaginário, se tornar um contraponto às campanhas institucionais preventivas que usam o discurso da negação, do "não", e por isso surtem pouco efeito junto ao público.

\section{NEGAÇÃO COMO AFIRMAÇÃO}

Schopenhauer coloca, em seu sistema filosófico O Mundo como Vontade e Representação, que aquilo que se conhece como felicidade seria apenas a interrupção temporária de um processo de infelicidade. Para ele, o prazer é momento fugaz de ausência de dor. Isso porque "viver é sofrer", e a possibilidade para a supressão da dor está na contemplação artística.

A alternativa apresentada por Schopenhauer de alterar o estado de consciência pela arte seria a forma de se esquivar da natureza humana, que, para ele, é animalesca, selvagem e terrível. "Nós o conhecemos [refere-se ao ser humano] unicamente no estado subjugado e domesticado denominado civilização: por isso nos assustam as eventuais erupções de sua natureza" (Schopenhauer, 1988, p. 195).

Por outro lado, Campbell vai afirmar que o que estamos procurando é uma experiência de estar vivos e não um sentido para a vida. Para ele, a experiência de estar vivo provoca ressonâncias no interior do próprio ser e em suas realidades mais íntimas (Campbell,1990, p. 5).

Os pontos de aderência de argumentações tão distintas de Schopenhauer e de
Campbell estão justamente na busca da experiência estética para reversão do mal-estar que a vida representa. A experiência estética aqui referida é a possibilidade de o indivíduo transcender a sua própria angústia.

É por isso que, através da arte, $o$ artista comunica aos outros a ideia apreendida. " $\mathrm{O}$ prazer estético é essencialmente único, seja originado por uma obra de arte ou de forma imediata pela intuição da natureza e da vida" (Schopenhauer, 1988, p. 25).

Campbell também vai encontrar nas narrativas mitológicas de diferentes sociedades antigas e, também, contemporâneas a oralidade como expressão estética em sintonia com a natureza, mencionada por Schopenhauer.

A questão que pode ser levantada é se os indivíduos buscam alterar o seu estado de consciência porque têm a percepção schopenhaueriana de que "viver é sofrer" ou querem experienciar, na perspectiva de Campbell, o ponto de quietude dentro de si mesmos. Em um, a experiência estética tem o objetivo de prolongar o intervalo da infelicidade que é constante. Em outro, a experiência seria a compreensão de que o lugar a ser encontrado está dentro de si próprio. Tanto para um como para o outro, qualquer uma dessas experiências somente seria possível ao se alterar o estado de consciência, saindo da realidade constituída e conhecida e se arriscando em outro estado de experimentações.

A contribuição de Campbell nesse sentido é que ele consegue provar que inúmeras culturas em diferentes processos históricos vão utilizar a mitologia como narrativas da subjetividade; seja, por exemplo, no grupo esquimó caribou, do norte do Canadá, ou nas sociedades tecnológicas contemporâneas, a experiência estética do ato de narrar como reelaboração das subjetividades sempre estará evidenciada, explícita ou implicitamente.

Nesse contexto, é possível perceber que a maioria das narrativas mitológicas traz a temática do uso de substâncias que alteram o estado de consciência ou servem como elementos de imobilidade física, mas não existencial, dos personagens. Entende-se a função do mito nesse aspecto como uma forma 
autônoma de pensamento e de vida, em que se situam em um plano diferente do intelecto, porém com a mesma importância dele.

Alterar o estado de consciência, nas narrativas mitológicas, é uma constante porque somente a partir daí é que se inicia o processo de mudança da condição existencial dos heróis e heroínas ou até mesmo dos anti-heróis e das anti-heroínas.

Quase sempre os personagens mitológicos deixam-se dopar como resultado de uma curiosidade incontrolável. O proibido, inevitavelmente, será transgredido, e o personagem central sofrerá transformações significativas pelo seu ato. É a manifestação do inconsciente. Tais abordagens estão no mito de Adão e Eva, Psiquê e tantos outros.

No mito de Narciso, narrado por Ovídio (século I d. C.), há a figura do jovem belo que está imerso em si mesmo. Etimologicamente, Narciso se origina do termo "narke", que significa flor de vida curta, com efeitos psicossomáticos. $\mathrm{O}$ termo se associa também à palavra "narcótico", que entorpece, provoca torpor.

$\mathrm{Na}$ narrativa, Narciso se apaixona por si mesmo ao se debruçar sobre uma fonte para beber água. "Ele apaixonou-se por sua imagem, porém não se relacionou com ela e, por isso mesmo, não conseguiu interação com mais ninguém" (Oliveira \& Oliveira, 2009, p. 177).

Narciso está entorpecido em si mesmo, está autocentrado, vítima de seu próprio narcótico. É um dos poucos personagens mitológicos que pagará com a própria vida esse entorpecimento. Isso se deve ao fato de ele perder-se em si próprio e ficar imóvel, diferente do herói que deve seguir a sua jornada.

Nas mitologias africanas, que têm uma interação visceral com a natureza, o uso da aguardente está intimamente ligado ao ritual da libação. Oti (pinga) é a bebida de Exu, assim como a maconha é a sua planta votiva. Ele representa o elemento que se posiciona entre os seres humanos e os orixás, sendo o primeiro a ser invocado nas cerimônias do culto. "Sua ferramenta, com sete pontas voltadas para cima, representa os sete caminhos do homem, os sete chacras captores e

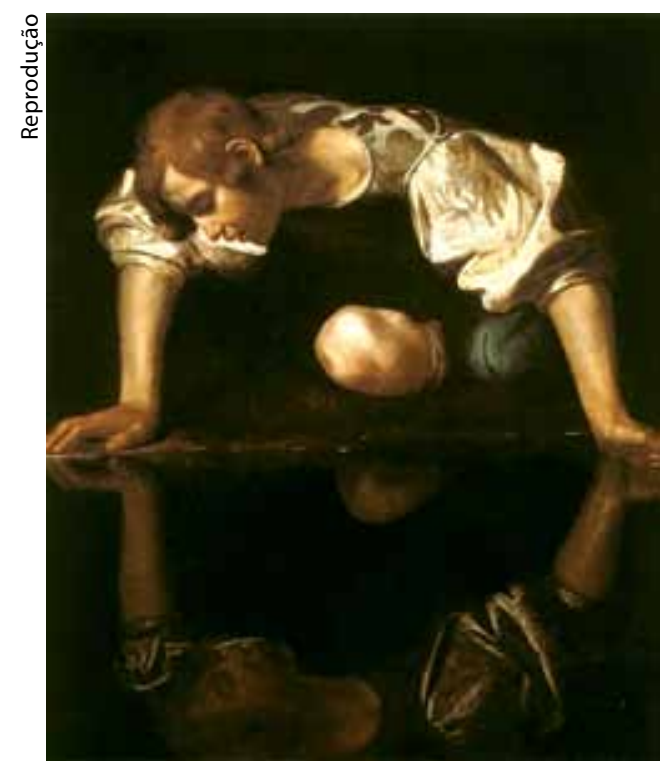

Narciso, de Caravaggio (1597-99)

distribuidores de energia, as sete cores e as sete auras" (Gondim, 2003, p. 137).

Exu é o mais humano dos orixás, sendo uma divindade de fácil relacionamento. “Tem o mesmo papel do deus Mercúrio, o mensageiro dos deuses do Olimpo" (Buonfiglio, 2004, pp. 75 e 76).

Tais construções arquetípicas permitem entender Exu com enorme capacidade de transitar entre o consciente e o inconsciente, tornando-se regente para aliviar ou agravar os casos de alcoolismo e uso de drogas, justamente as substâncias que alteram o estado de consciência.

Na comunicação midiática, a publicidade talvez seja a mais catalisadora e suscetível dessas percepções arquetípicas e mitológicas, construídas por diferentes sociedades ancestrais. E é sobre ela que este artigo se debruça para fazer a interseção entre mitologia, publicidade e uso de substâncias, como as bebidas alcoólicas. Por esse motivo, não há intenção aqui de analisar a publicidade pelo olhar sociológico ou por um viés marxista e a sua interação com o capitalismo. O principal enfoque é a compreensão da publicidade como catalisadora, na contemporaneidade, das narrativas mitológicas.

O estudo de caso feito neste artigo é o da marca de uísque Johnnie Walker. Talvez 
seja a marca que melhor concentra em suas peças publicitárias a ideia de arquétipos. $\mathrm{O}$ ícone da marca, o Striding Man (o Andarilho), que foi criado em 1908, e o conceito "Keep walking" ("Continue caminhando"), desenvolvido pelas agências Diageo e BBH.

O Andarilho de Johnnie Walker tem muito da jornada do herói. O herói, no sentido da narrativa mitológica, é aquele que evidencia a falta, a perda de algo (quase nunca algo material, palpável), e sai à procura, perfazendo um círculo de partida e chegada. "Esse é o motivo básico do périplo universal do herói - ele abandona determinada condição e encontra a fonte da vida, que o conduz a uma condição mais rica e madura" (Campbell, 1990, p. 132).

O signo do Striding Man não é apenas o alterego do fundador da marca do uísque, John Walker. O Andarilho é o arquétipo daquele que procura o imponderável, a si mesmo. É interessante que o conjunto de peças publicitárias da marca trabalha com as dimensões existencialistas de interior e exterior na mesma proporção e, por mexer com elementos tão subjetivos, cria um vínculo imediato com o público e efetiva a conexão de que o ato de sorver o uísque Johnnie Walker equipara-se à ritualização da jornada do herói, ou seja, do próprio indivíduo. Uma jornada que ele fará sozinho. Por isso, sempre o protagonista está só e reflexivo, mas decidido a partir para algum lugar, diferente daquele lugar naturalmente dado.

Esse ato de partir, representado pelo ícone do Andarilho, é tão explícito que foi várias vezes redesenhado no decorrer da história publicitária da marca. Nas primeiras versões ele andava da direita para a esquerda. A ideia de que esse "caminhar" deve ser progressivo fez com que o movimento da figura fosse da esquerda para a direita, obedecendo ao sentido de leitura ocidental e também sugerindo que essa jornada é uma projeção para o futuro.

Outra característica é que o ícone foi perdendo as formas do desenho original de um homem com trajes mais pesados e formais, como foi a primeira versão em 1909, para o desenho de um homem vestido com roupa de montaria. Porém, essa versão de 1925 foi sofrendo transformações até que, em 2005, a figura continua a mesma, porém mais esmaecida. Essa última transformação permite que o público se projete no ícone, ao qual, por estar estilizado, não se pode atribuir sequer o seu grupo étnico. Ou seja, qualquer indivíduo pode se projetar no Andarilho.

Essa busca de si mesmo é evidenciada pela marca quando lança a campanha "Eu não sou o futuro. Você é". O roteiro da cam-
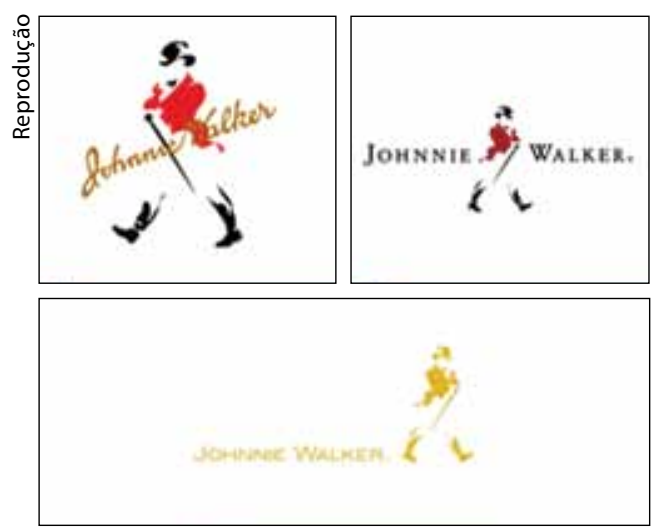

Nas primeiras versões, o Striding Man (Andarilho) andava da direita para a esquerda. Nas versões mais contemporâneas, a sua direção é invertida, sugerindo projeção para o futuro

\section{Linha do tempo do ícone da marca de uísque Johnnie Walker, o Striding Man}

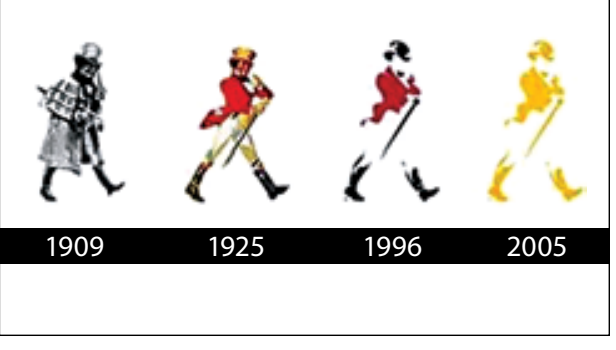




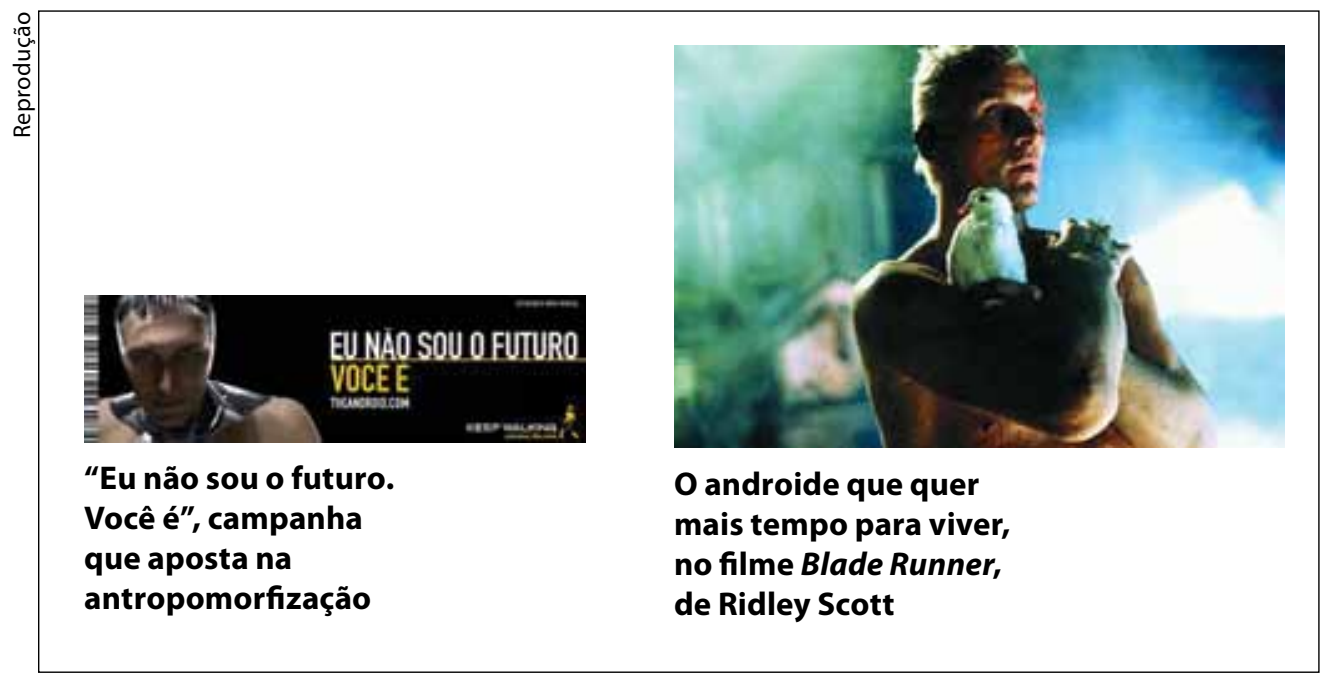

panha envolve um androide com rosto e corpo humanos, mas com a parte posterior da sua cabeça deixando transparecer os dispositivos robóticos assim como alguns outros membros. Ou seja, é um ser em construção. Ele diz, quase em um lamento, o quanto desejaria ser humano:

"Eu sou mais rápido que você. Eu sou mais forte que você e com certeza vou durar muito mais que você. Você pode pensar que eu sou o futuro, mas está errado. Você é o futuro. Se eu pudesse desejar alguma coisa, desejaria ser humano pra saber o que significa ter sentimentos, ter esperanças, ter angústias, dúvidas, amar. Eu posso alcançar a imortalidade, basta não me desgastar. Você também pode alcançar a imortalidade, basta fazer apenas uma coisa notável... [na sequência aparece o slogam "Keep walking" ("Continue andando") e a assinatura Johnnie Walking]" (Johnnie Walker, s.d.).

A campanha publicitária "The Android", de Johnnie Walker, lembra muito a angústia dos androides (replicantes) do filme Blade Runner, de Ridley Scott, que desejam um tempo a mais de vida, antes que sejam, na concepção deles, prematuramente desativados. No filme, um dos replicantes, o líder Roy Batty (interpretado pelo ator Rutger Hauer), o mais afoito pela vida e por isso mesmo o mais cruel, na iminência de ser desativado, tem uma pomba nas mãos e na outra o seu perseguidor humano, Deckard (interpretado por Harisson Ford), o que induz o público a pensar que irá matar os dois. No entanto, o que prevalece é a vida. No filme, antes de "morrer", o androide solta a pomba e deixa o seu perseguidor viver.

A cena do replicante de Ridley tendo um animal nas mãos e deixando-o ileso é recriada pelo androide de Johnnie Walker, que segura uma borboleta e depois a solta, lembrando o quanto desejaria ser humano. É a metáfora da transcendência.

Essas construções antropomórficas comovem porque os androides que valorizam tanto a condição de ser humano na verdade se confrontam com as dúvidas existenciais que o próprio ser humano tem de sua vida, considerada por ele um peso existencial e sem sentido. Por esse motivo, esse ser humano precisa alterar o seu estado de consciência (sair de si mesmo) para suportar o ato de viver. Daí as metáforas da borboleta, do androide de Johnnie Walker, e da pomba, do replicante de Blade Runner.

$\mathrm{O}$ androide de Johnnie Walker ainda explicita que o humano, para alcançar a imortalidade, precisa apenas fazer uma coisa notável, "[...] keep walking”. Porém, como peça publicitária, o subtexto associa o uísque Johnnie Walker à ideia de um elixir que 


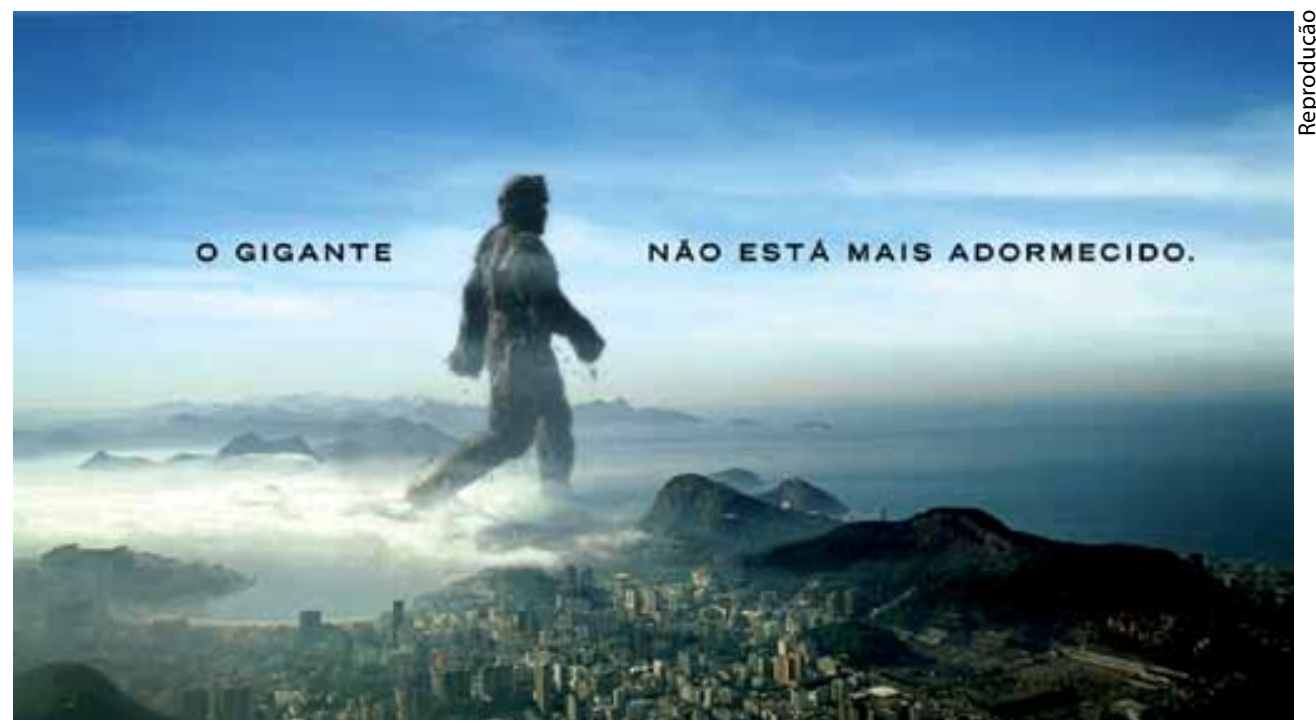

O Pão de Açúcar, antropomorfizado, sai para a jornada do herói

dará forças para a longa jornada. Do ponto de vista metafórico, essa construção (a ritualização antes, durante e depois da caminhada) é encontrada em quase todas as mitologias da jornada do herói.

Outra campanha publicitária do uísque Johnnie Walker, feita exclusivamente para o público brasileiro, também com personagem antropomórfico, é o "O gigante não está mais adormecido". Nessa campanha, o maciço rochoso Pão de Açúcar, na cidade do Rio de Janeiro, toma forma humana e se levanta em direção ao mar. É como se despertasse de repente, atendendo a um chamado, e saísse em sua jornada, em direção ao mar. A campanha faz uma analogia com o avanço do desenvolvimento econômico brasileiro. Porém, o simbolismo mitológico (antropomórfico) é destacado na descrição do vídeo feito pela agência criadora da campanha:

"No início dos tempos, na parte sul das Américas, habitava um gigante. Um dos poucos que andava sobre a Terra.

Gigante pela própria natureza, e sendo natureza ele próprio, era feito de rochas, terra e matas, que moldavam sua figura. Pássaros e bichos pousavam e viviam em seu corpo e rios corriam em suas veias. Era como um imenso pedaço de paisagem que andava e tinha vontade própria.
Caminhava com passadas vastas como vales e tinha a estatura de montanhas sobrepostas. Ao norte, em seu caminho, encontrava sol quente e brilhante nas quatro estações do ano. Ao sul, planaltos infindáveis. A oeste, planícies e terras cheias de diversidade. E a leste, quilômetros e quilômetros de praias onde o mar tocava a terra gentilmente, desde sempre. Havia também uma floresta como nenhuma outra no planeta. Tão grande, verde e viva que funcionava como o pulmão de todo o continente à sua volta. Mesmo diante de tudo isso, um dia, enquanto caminhava, o gigante se inquietou.

Parou então à beira-mar e ali, entre as águas quentes do Atlântico e uma porção de terra que subia em morros, deitou-se. E, deitado nesse berço esplêndido, olhou para o céu azul acima se perguntando: 'O que me faz gigante?'.

Em seguida, imaginando respostas, caiu em sono profundo.

Por eras, que para os gigantes são horas, ele dormiu. Seu corpo gigantesco estirado, o joelho dobrado formando um grande monte, uma rocha imensa denunciando seu torso titânico e a cabeça indizível, coberta de árvores e limo.

Dormiu até se tornar lenda no mundo. Uma lenda que dizia que o futuro pertence ao gigante, mas que ele nunca acordaria e que 
o futuro seria para ele sempre isso: futuro. No entanto, com o passar do tempo ficou claro que nem mesmo as lendas devem dizer 'nunca'. Depois de muito sonhar com a pergunta sobre si, o gigante finalmente despertou com a resposta. Acordou, ergueu-se sobre a terra da qual era parte e ficou de frente para o horizonte. Tirou então um dos pés do chão e, adentrando ao mar, deu um primeiro passo. Um passo decidido em direção ao mundo lá fora para encontrar seu destino. Agora sabendo que o que faz um gigante não é o seu tamanho, mas o tamanho dos passos que ele dá” (Johnnie Walker, 2012.)

Nessa descrição fica explícito o uso das narrativas mitológicas como tendência da marca Johnnie Walker, que utiliza a antropomorfização como uma forma de conciliar o ser humano na sua condição de natureza e ao mesmo tempo de artífice. O slogan, que enfatiza a ideia de movimento, de caminhar, "Keep walking", está presente nessas construções.

No entanto, como conciliar o ato de caminhar com o ato de ingerir álcool? As campanhas publicitárias analisadas retomam as metáforas da ritualização, em que a bebida transforma-se em importante elemento de alteração do estado de consciência para se atingir uma nova consciência.

Uma característica interessante das peças publicitárias de Johnnie Walker é a opção por fixar o conceito em primeiro plano e não o produto em si. Em todas as peças, as qualidades do uísque não são exaltadas, mas o conceito moral é que está agregado. Ou seja, quem opta pela marca é um Andarilho, alguém que está sempre se projetando para o futuro, que modifica a própria inércia.

Se a publicidade utiliza-se dos arquétipos para sincronizar-se com o indivíduo, as campanhas de prevenção governamentais ou da sociedade civil têm enormes dificuldades nesse processo.

Ao analisar as mensagens das campanhas de prevenção ao uso do álcool é possível perceber que a palavra "não" é quase sempre utilizada, induzindo a ideia de proibição.
Em quase todos os arquétipos mitológicos, o "não" tende a ser interpretado pelo personagem como um "sim", pois a sua meta é a transgressão.

\section{CONSIDERAÇÕES FINAIS}

Não restam dúvidas de que os problemas do uso indiscriminado de drogas (lícitas ou ilícitas) têm se constituído em um problema social relevante. Porém, é necessário responder a uma questão básica: se o álcool e outras substâncias que alteram o estado de consciência são maléficos, por qual motivo cada vez mais pessoas querem fazer uso deles?

Desde os primórdios as narrativas mitológicas inserem em seus contextos a necessidade de heróis e heroínas alterarem o seu estado de consciência. A arte surge justamente para ser a possibilidade de tirar o indivíduo do seu estado normal e de conforto, assim como as substâncias mágicas, químicas, da natureza e outras. Enquanto artífice, o ser humano quer recriar o seu meio e ressignificar o seu próprio fluxo, e tal empreitada exige dele uma constante alteração do seu estado de consciência.

As campanhas de prevenção ao uso de drogas, como o álcool, em contraponto às publicidades, trabalham muito nas perspectivas da negação e da proibição. Quase sempre são impositivas, imperativas e maniqueístas. Por isso, na maior parte das vezes, perdem o seu poder de prevenir até que não são mais percebidas.

As publicidades, ao contrário, fazem uso das construções simbólicas e arquetípicas. Ao estudar as campanhas da Johnnie Walker é possível perceber o quanto elas trabalham os elementos arquetípicos, antropomórficos, que de certa forma inebriam. O que chama a atenção é que o seu "Keep walking" dispensa tradução porque toda a mensagem não verbal sinaliza para a ideia desse "Continue caminhando". Outro elemento intrigante é que em nenhuma das mensagens audiovisuais aparece o seu produto, que é o uísque. O que é trabalhado e está em foco é o conceito. 
BUONFIGLIO, Mônica. Orixás, Anjos da Natureza: um Estudo sobre os Deuses do Candomblé. São Paulo, Mônica Buonfiglio, 2004.

CAMPBELL, Joseph. O Poder do Mito. São Paulo, Palas Athena, 1990.

GONDIM, Airton Barbosa. Seu Guia no Candomblé. Salvador, AB Gondim, 2003.

JOHNNIE WALKER. 2012. Disponível em: http://www.johnniewalker.com/es-es/

AgeGateway.aspx. Campanha The Android. Disponível em: http://www.youtube.com/ watch?v=D57NTsAfhCY.

OLIVEIRA, Bosco; OLIVEIRA, Ingrid C. Mitologia e Vivências Humanas. Rio de Janeiro, Wak, 2009.

SCHOPENHAUER, Arthur. "Parerga e Paralipomena", in Schopenhauer. São Paulo, Nova Cultural (Os Pensadores), 1988.

SCOTT, Ridley. Blade Runner: o Caçador de Androides. Filme (ficção científica). EUA, Warner Bros, 1982.

THWAITEST, Peter; e GAMA, Alexandre. Keep Walking, Brazil/O Gigante Não Está mais Adormecido. Brasil/Estados Unidos/Inglaterra. Produção: Zohar/Gorgeous. Agências: Neogama/BBH, 2011. Disponível em: http://quasepublicitarios.wordpress. com/2011/10/13/keep-walking-brazil. 